\title{
What are the Benefits of Continued Purchasing through the Internet? A Study of South Korean Consumers
}

\author{
Kanokwan Atchariyachanvanich, Noboru Sonehara and Hitoshi Okada \\ National Institute of Informatics 2-1-2 Hitotsubashi Chiyoda-ku, Tokyo, 101-8430 Japan
}

\begin{abstract}
Since keeping the customer purchasing a product/service is essential to maintaining the profitability of any business, the continuance of purchasing through the Internet is vital to online business. This study is one of the few attempts to investigate the perceived benefit factors affecting customers' intention to continue purchasing through the Internet. According to a multiple regression analysis of online questionnaires filled out by 998 online customers in South Korea, extrinsic benefits measured in terms of time and money savings as well as intrinsic benefits measured in terms of pleasure, novelty, and fashion involvement have strong effects on the repurchase intention. Our findings indicate that customer retention must be promoted in Internet shopping by guaranteeing not only extrinsic benefits but also intrinsic benefits. This study discusses the relevant techniques of providing those benefits to customers and guidelines for future research.
\end{abstract}

Keywords: repurchase intention, benefit, Internet shopping, extrinsic benefit, intrinsic benefit

\section{Introduction}

The government of South Korea is actively promoting electronic commerce (EC), in part by providing government support, and the total volume of e-commerce increased from $\$ 47.93$ billion in 2000 to $\$ 99.15$ billion in 2001 [21]. The growth rate of business- to-customer (B2C) EC was $252.2 \%$ in 2001. Moreover, the total EC sales during the second quarter of 2002 equaled 1.355 trillion won, an increase of $52.6 \%$ compared to that of 2001 [21]. Because of the rapid growth of the EC market and support from the government, South Korea has played an important role in the global EC market.

However, there are obstacles to $\mathrm{B} 2 \mathrm{C}$ adoption in the area of operation of Internet stores, including high logistics costs, lack of marketing strategy, limited product range and service differentiation, and lack of features for customers on the website [21]. As these may cause online customers to stop shopping through the Internet, an investigation of the reasons that consumers choose to purchase again through the Internet is also important. Despite the need to succeed in business [23], the factors affecting the continuance of purchasing through the Internet have rarely been explored. Recent studies show that investigating such factors in an online environment can help us to create an effective customer-retention strategy and to determine the impact of the identified factors on the products and services offered by Internet shops $[10,12]$.

The fundamental reason for the existence of true market segments is the benefit that people derive from consuming a given product [24], and the benefits of Internet shopping for customers have been discussed in the litera- ture. The benefits include time saving and the convenience of shopping without being restricted by store hours or location. These extrinsic benefits serve as a means to help customers achieve other outcomes, for example, to reduce the time spent shopping and to gain convenience or efficiency. Shang et al. [22] found that an extrinsic factor, perceived usefulness, was not an antecedent of purchasing through Internet shopping, but rather, intrinsic motivations, fashion and cognitive absorption, were more important than extrinsic ones. Considering this, the extrinsic benefit and intrinsic benefit customers get by shopping online can be used as a measure of the willingness of a customer to continue purchasing from an Internet shopping website. While prior studies have examined the benefits that encourage a customer to purchase through the Internet, this study examines the extrinsic and intrinsic benefits affecting the customer's intention to continue purchasing items through the Internet. The underlying factors among the variables can be discovered by applying exploratory factor analysis. These factors were investigated by using multiple regression analysis to determine whether they had any relationship with continuance of purchasing behavior.

In the following section, we discuss the literature that is relevant to the continuance of purchasing behavior and the benefits of Internet shopping. The methodology, measurement development, and reliability analysis are described in the third and the fourth sections. The results are discussed in the fifth section. Finally, we present our conclusions and discuss the limitations of the present research and guidelines for future research. 


\section{Intention to Continue Purchasing through the Internet}

Many studies on customer behavior, in particular, customer satisfaction and intention to continue purchasing, have applied expectation-confirmation theory in the EC context. Kim et al. [4] proposed a framework combining trust, expectation, and satisfaction. Their findings showed that customer's trust and expectations are positively related with satisfaction which has a positive influence on the intention to repurchase. Lee et al. [12] argued that retaining customer loyalty is vital to make Internet users visit Internet shopping websites again. Trust and low transaction cost help to increase customer loyalty towards an Internet shopping website. On the other hand, Koufaris [17] used customer intention to return, not actual return visits to measure loyalty. He found that shopping enjoyment and perceived usefulness are positively significant to the customers' intention to return to visit online bookstore. Liang and Lai [27] examined the effect of design quality on consume choice of online bookstores. Their results showed that design quality is as important as product price to make customers visit and purchase again.

Chung and Lee [10] indicated that product perceptions, customer service, perceived ease of use, site image, promotion, communications environments, and overall customer satisfaction for the Internet shopping stores are positively correlated with the repurchase intention, but perceived consumer risk has a negative relationship with the repurchase intention.

In the literature, perceived benefit has not yet been examined in the context of behavior of consumers who may continue to purchase through the Internet. Hence, we believe that our study on the perceived benefits affecting continuance of purchasing through Internet shopping is unique.

Bhattacherjee [1] examined the antecedents of customers' intention to continue to use an online brokerage, which is a kind of EC service. By adding a new factor, customer loyalty, to that study's method, Atchariyachanvanich et al. [14] developed a model of repurchasing factors of Internet shopping and examined the key factors underlying customers' intention to continue purchasing items through the Internet. They focused on five factors including confirmation, satisfaction, perceived usefulness, perceived incentives, and customer loyalty, which accounted for $46 \%$ of the variation in the repurchase intention. This means that there must be other variables that have an influence as well. Therefore, the current study examines a new factor, perceived benefit that affects the customer's intention to continue purchasing through Internet shopping.

\section{Benefits of Internet Shopping}

According to Haley's study [24], the fundamental reason for the existence of true market segments is the benefit that people derive from consuming a given product. He also argued that benefits sought by consumers determine their behavior much more accurately than do demographic characteristics or volume of consumption. He pointed out that "a substantial group of people must be interested in your specific set of benefits before you can make progress in a market". This implies that online customers must be interested in Internet shopping's benefits before Internet shops can make progress in a market aspect such as customer retention. Once an online customer perceives the benefits of purchasing items through the Internet, he or she will tend to continue purchasing online. This brings us to a new factor, perceived benefit, which may affect the customer's intention to continue purchasing through the Internet.

Two kinds of benefit, extrinsic and intrinsic, were identified by previous studies in the information systems domain. Davis et al. [7] indicated that extrinsic motivation (usefulness) and intrinsic motivation (enjoyment) influenced a person's intention to use a computer. Hui et al. [15] identified seven benefits (i.e. monetary saving, time saving, self-enhancement, social adjustment, pleasure, novelty, and altruism) that could motivate customers to disclose their personal information to Internet businesses. In the domain of Internet shopping, the intrinsic factor in terms of fashion involvement was more important than extrinsic factors in explaining why customers shopped online [22]. Although the largest number of benefits has been identified in the context of online information disclosure [15], they have not been examined in the context of Internet shopping. Therefore, in the light of previous studies [7, 15, 22], we propose perceived benefits in terms of extrinsic and intrinsic benefits.

\subsection{Extrinsic benefits}

Extrinsic benefits offer a means with which customers can achieve other goals [15]. Since extrinsic motivation refers to the performance of an activity because it is perceived to be helpful in gaining valued outcomes that are distinct from the activity itself [7], extrinsic benefits pertain to the benefits obtained from the outcome of performing the activity, but are distinct from the activity itself. Such benefits can motivate a consumer's intention to perform an action to gain benefits that serve as a means to reach other outcomes. Four types of extrinsic benefit classified in Hui et al.'s study [15] were adapted to the domain of consumer behavior in Internet shopping.

Time saving refers to benefits that provide better efficiency or convenience. The benefits of saving time are to reduce time spent on and to achieve convenience in shopping. Time saving may affect online customers because it allows them to carry out more activities. As Internet shopping reduces the customers' time needed to obtain information about product prices and product offerings [2, 13], it may encourage them to shop online again. Thus, 
we propose that:

H1: Time saving positively affects a customer's continuance of purchasing behavior in Internet shopping.

Money saving includes means for customers to reduce money spent on shopping and to gain free gifts such as discounts, vouchers, loyalty points, etc.. Perceived incentives in terms of free gifts, free coupons, and points were found to significantly influence the intention to repurchase in Internet shopping [14]. Customers are generally concerned about the cost of purchasing a product or service. If Internet shopping can help them save money in purchasing items, they may come back to purchase again. Therefore, we propose that:

H2: Money saving positively affects a customer's continuance of purchasing behavior in Internet shopping.

Social adjustment refers to the customers' need to establish social identities by assimilating into desired social groups. In general, customers have a desire to align with others who are like-minded [15]. Internet shopping provides additional services to satisfy such a desire. For example, a beauty club webpage is made for online customers who like purchasing beauty products and also to exchange and share knowledge about those products. This may motivate online customers to visit the Internet stores and purchase from them again. Thus, we propose that:

H3: Social adjustment positively effects a customer's continuance of purchasing behavior in Internet shopping.

Self-enhancement refers to means for customers to assert their self-concept or to maintain self-esteem in relation to others. Hui et al. [15] asserted that Internet businesses can possibly make use of such characteristics by bundling self-enhancement benefits with requests for personal information. In addition, the consumer behavior of an individual will be directed toward enhancing self-concept through the consumption of goods as symbols [16]. For example, online customers will be recognized by the Internet store on their next purchase after they have registered as members of the Internet store. We posit that:

H4: Self-enhancement positively affects a customer's continuance of purchasing behavior in Internet shopping.

\subsection{Intrinsic Benefits}

Intrinsic benefits refer to the benefits gained from purchasing through Internet shopping, apart from any purchase consequences that may be anticipated, and are ends in themselves to customers [7, 15]. When a customer considers the intrinsic benefits, they perform a task simply because the performance of the task offers them benefits. Previous studies $[15,22]$ indicate that online customers seek out consumption experiences obtainable from purchasing (pleasure, novelty, and fashion involvement) as ends in themselves.

Pleasure is defined as the extent to which the activity of purchasing in Internet shopping is enjoyable and pleasant in its own right, apart from any purchase consequences that may be anticipated [7, 15, 17]. Jarvenpaa and Todd [25] show that Internet customers miss the fun and atmosphere of shopping in traditional stores. In response to this problem, Aberg and Shahmehri [11] developed the Human Web Assistant to provide efficient user support to make a website more fun to use, to increase the customers' trust in the website, and to improve the website's atmosphere. In addition, virtual reality storefronts offer online customers additional ways to find enjoyment through Internet shopping. This perception of pleasure may make customers more likely to purchase again in Internet shopping. Thus, we hypothesize that:

H5: Pleasure positively affects a customer's continuance of purchasing behavior in Internet shopping.

Novelty focuses on means that help customers fulfill their innate needs for exploration or information. Hui et al. [15] indicated that the curiosity of customers can be stimulated by an appropriate level of information complexity. As Internet shopping websites provide plenty of information about products, support, payment methods, and delivery channels, these benefits may make customers visit Internet shopping websites again. This leads to the hypothesis that:

H6: Novelty positively affects a customer's continuance of purchasing behavior in Internet shopping.

Fashion involvement is defined as the degree to which the activity of purchasing in Internet shopping enables customers to make purchases according to their own fashionable behavior. Shang et al. [22] assumed that shopping is a fashionable behavior and used fashion involvement to conceptualize the effects of social influence. Their study found that fashion involvement was more important than extrinsic factors in explaining the behavior of online customers. Therefore, we propose that:

H7: Fashion involvement positively affects a customer's continuance of purchasing behavior in Internet shopping.

\section{Methodology}

Based on the well-established framework for developing measures of a construct [8], this study specifies the domain of the construct (i.e., Internet shopping benefits), generates items from literature reviews, collects data, purifies items, assesses reliability and validity, and develops norms.

\subsection{Data collection}

This study targeted potential online users who have pur- 
chased a product or service through Internet shopping and intend to continue purchasing through it. The percentages of Internet users' survey conducted in 2006 by the National Internet Development Agency of Korea [19] were first used as a condition to screen our potential online customers or potential respondents. Then the percentages of age groups and gender of our respondents were set equal to those of the Internet users. Doing so avoids an excess of answers from highly educated respondents or young respondents and ensures that the respondents will be selected randomly.

As the web-based survey was conducted in South Korea, a Korean version of the questionnaire was used. The questionnaire, originally written in English, was translated into Korean by bilingual speakers whose native language was Korean and whose background was IT-oriented. The questionnaire was then translated back into English by another bilingual speaker whose native language was English and whose background was also IT-oriented. The English versions were then compared, and no item was found to pertain to a specific cultural context in terms of language or to a specific IT-related context in terms of background translation.

The survey process consisted of four steps. First, the percentages of age groups and gender were set equal to those of the Internet users of the computer and Internet usage survey [19]. The segments of respondents in the database were set to these percentages. Then an invitation to fill out an online questionnaire was electronically mailed to registered opt-in-mail members of the partner of 'goo Research' of NTT Resonant Inc., Japan on March 19, 2007. Secondly, the respondents answered a pre-test questionnaire posted on the website during March 20-23, 2007. This pre-test was to screen online users who had purchased a product or service through Internet shopping and might intend to continue purchasing through it. Thirdly, if the percentage of pre-test respondents in each age group and gender was higher than the segments set in step 1, the system would randomly select the respondents from among each segment. The potential respondents, who were randomly selected, were sent the opt-in-mail with the invitation for the post-test questionnaire attached. Lastly, they answered the questionnaire during March 24-28, 2007. The percentages of target respondents were recorded until they reached the segments set in step 1 . Hence, the system automatically stopped gathering the online questionnaire when the segments were completed. After completing all steps, 998 target responses had been completed and matched target respondent segments set in step 1 . The respondents received a point as a reward if they completed the online questionnaire.

To replicate the distribution of online customers of Internet shopping in South Korea [20], sample weighting* was applied to assign a weighted variable to each response.
The weighted variable was based on the percentages of gender and age group [20]. Then each response in the dataset was weighted by their weighted variables. As a result, the distribution of the dataset became applicable to the distribution of online customers of Internet shopping in South Korea. Table 1 presents the respondents demographic data.

Table 1. Demographic data of respondents $(N=998)$

\begin{tabular}{|c|c|c|}
\hline \multicolumn{2}{|c|}{ Category } & Percentage(\%) \\
\hline \multirow{2}{*}{ Gender } & Male & 54.1 \\
\hline & Female & 45.9 \\
\hline \multirow{2}{*}{$\begin{array}{l}\text { Marital } \\
\text { Status }\end{array}$} & Single & 56.7 \\
\hline & Married & 43.3 \\
\hline \multirow{6}{*}{ Age } & $15-19$ & 27.3 \\
\hline & $20-29$ & 22.3 \\
\hline & $30-39$ & 23.9 \\
\hline & $40-49$ & 11.1 \\
\hline & $50-59$ & 8.6 \\
\hline & $>=60$ & 6.7 \\
\hline \multirow{5}{*}{$\begin{array}{c}\text { Annual } \\
\text { income } \\
\text { (1Mllion } \\
\text { KRW= } \\
1,078 \\
\text { USD) }\end{array}$} & $\leqslant 2,156$ USD & 18.2 \\
\hline & $2,157-5,390$ USD & 42.3 \\
\hline & 5,391-8,624 USD & 14.3 \\
\hline & $\geqslant 8,625$ USD & 3.3 \\
\hline & Missing value & 21.9 \\
\hline \multirow{7}{*}{$\begin{array}{l}\text { Education } \\
\text { level }\end{array}$} & Secondary School & 16.2 \\
\hline & High School & 30.8 \\
\hline & Vocational School & 0.3 \\
\hline & College & 10.0 \\
\hline & Bachelor Degree & 37.3 \\
\hline & Master Degree & 4.3 \\
\hline & Doctoral Degree & 1.1 \\
\hline
\end{tabular}

\subsection{Measures}

The post-test questionnaire consisted of two sections. The first section was designed to gather demographic characteristics including age, gender, education level, personal monthly income, and Internet activities. In the second section, the measurement items were developed from previous studies on EC benefits for customers [26] and the literature discussed in Section 3. In addition, new measurement items were adapted from Hui et al.'s study [15]. The items were modified to fit the domain of Internet shopping when necessary. A 19-item scale measuring perceived benefits and one item measuring overall customers' continuance of purchasing behavior in Internet shopping were developed (see Appendix A). The scale items of perceived benefits were classified into two major

* Sample weighting is used to correct disproportional sample sizes and adjust the collected data to represent the population from which the sample was drawn [3]. During a period of data collection, the population of online customers [20] is the newest one that is suitable for doing sample weighting. 
categories: extrinsic benefits and intrinsic benefits. The respondents were requested to evaluate the level of their agreement with each scale item on a five-point Likert scale ranging from (1) "strongly disagree" to (5) "strongly agree". Table 2 represents the descriptive statistics of all scale items. Each item's mean values ranged between 3.14 and 4.26 , while the standard deviation values were between 0.70 and 1.05 . The dependent variable representing the intention to continue purchasing through the Internet could be scaled by three items identified in [14].

\subsection{Exploratory Factor Analysis}

Before performing an exploratory factor analysis (EFA), one needs a strong conceptual foundation to support the assumption that a structure does exist [9]. Hence, it must be certain that the data matrix has sufficient correlations to justify the application of factor analysis. Kaiser's measure of sampling adequacy (MSA) was used to quantify the degree of intercorrelations among the variables and the appropriateness of factor analysis. The overall MSA was 0.90. In addition, all individual variables' MSAs ranged from 0.500 to 0.845 . This clearly suggests that factor analysis can be used to extract research factors [9].

EFA was applied to the 19 benefit items by using the principle component extraction method and an oblimin with Kaiser Normalization rotation. The criteria used in this analysis are outlined as follows [9]:

1. Factors with eigenvalues or latent roots of all components should be greater than 1.0,

2. Communalities of all items should be more than 0.5 ;

3. The factor loadings of \pm 0.50 or greater are considered necessary for practical significance; and

4. Cronbach's alpha values of each factor extracted and overall measure should be greater than 0.7 .

The EFA extracted items into four factors that passed all criteria. To justify the extracted factors from the factor analysis, a reliability analysis was performed on items classified under each extracted factor as well as the overall scale. Only the alpha of the fourth factor was lower than 0.7. Consequently, these factors provide a reliable and consistent measure of the intended dimensions and no further elimination of items appears necessary. Table 3 shows the final factors with meaningful factor names, loadings, communality, Cronbach's alpha, eigenvalues, and percentage of trace. Factor 1 with six items, factor 2 with five items, factor 3 with six items, and factor 4 with two items were loaded. Each factor was subjectively named from the nature of the grouped items with significant loadings:

1. Factor 1 Intrinsic factor: $I 1, I 2$, and $I 3$ - Pleasure; I4 and I5-Novelty; I8-Fashion involvement. I6 and $I 7$ were dropped from this factor because their factor loadings were less than the accepted level.

2. Factor 2 Extrinsic factor: E1, E2, and E4-Time saving. E3 was dropped from this factor because of its unaccepted factor loading.

3. Factor 3 Extrinsic factor: E7, E8, E9, and E10-Social adjustment and self-enhancement. E11 was dropped from this factor because of its unaccepted factor loading.

4. Factor 4 Extrinsic factor: E5 and E6-Money saving.

Table 2. Descriptive Statistics of Data $(N=998)$ (E1-Convenience; E2-Save time; E3- Shop/find information easier; E4- Shop/find information more quickly; E5- Save money; E6- Offer lower prices; E7Interact with other customers in EC communities; E8-Interact with like-minded people; E9- Recommendation from like-minded people; E10-Exchange idea and compare experience; E11-To be recognized when purchasing again; I1-Enjoy using Internet shopping; I2-Be happy when using Internet shopping; I3-Be delighted with experience of Internet shopping; I4-Stimulate curiosity; I5-Provide customers with the product/supplemental information that they are interested in; I6- Offers options to perform task in different ways; I7- Opportunity to make oneself appear fashionable; I8-Boast of being the first one who possess a product)

\begin{tabular}{|c|c|c|}
\hline Items & Mean & Std. Deviation \\
\hline E1 & 4.26 & 0.70 \\
\hline E2 & 4.07 & 0.85 \\
\hline E3 & 3.77 & 0.75 \\
\hline E4 & 4.04 & 0.73 \\
\hline E5 & 3.68 & 0.88 \\
\hline E6 & 3.94 & 0.76 \\
\hline E7 & 3.49 & 0.83 \\
\hline E8 & 3.62 & 0.80 \\
\hline E9 & 3.65 & 0.76 \\
\hline E10 & 3.63 & 0.76 \\
\hline E11 & 3.43 & 0.81 \\
\hline I1 & 3.73 & 0.84 \\
\hline I2 & 3.36 & 0.76 \\
\hline I3 & 3.55 & 0.75 \\
\hline I4 & 3.36 & 0.85 \\
\hline I5 & 3.50 & 0.75 \\
\hline I6 & 3.33 & 0.76 \\
\hline I7 & 3.61 & 0.75 \\
\hline I8 & 3.14 & 1.05 \\
\hline
\end{tabular}

Discriminant validity is the extent to which a factor is truly distinct from other factors. Indeed, Hair, et al. [9] suggested that average variance extracted can be used to evaluate discriminant validity. To demonstrate the discriminant validity of the constructs in this study, the square root of average variance extracted for each factor should be greater than the correlations between that factor and all other factors. Table 4 shows the correlation matrix 
of the factors. The assessment of discriminant validity indicates that the square root of average variance extracted of all factors is greater than the correlations between that factor and all other factors.
Overall, these results provide empirical support for the reliability and convergent validity of the items of our research model.

Table 3. Component Matrix of Exploratory Factor Analysis $(N=998)$

\begin{tabular}{|c|c|c|c|c|c|}
\hline \multirow{2}{*}{ Items } & \multicolumn{4}{|c|}{ Factor Loadings } & \multirow{2}{*}{ Communality } \\
\hline & 1 & 2 & 3 & 4 & \\
\hline E1: Convenience & 0.169 & 0.718 & 0.027 & -0.012 & 0.610 \\
\hline E2: Save time & 0.064 & 0.781 & -0.032 & 0.038 & 0.644 \\
\hline $\begin{array}{l}\text { E3: Shop/find information } \\
\text { easier }\end{array}$ & -0.037 & 0.435 & 0.195 & 0.283 & 0.424 \\
\hline E4: Shop/find information more quickly & 0.033 & 0.662 & 0.074 & 0.109 & 0.537 \\
\hline E5: Save money & -0.143 & 0.221 & -0.024 & 0.697 & 0.565 \\
\hline E6: Offer lower prices & 0.009 & 0.229 & 0.092 & 0.549 & 0.470 \\
\hline $\begin{array}{c}\text { E7: Interact with other customers in EC } \\
\text { communities }\end{array}$ & -0.007 & 0.041 & 0.800 & -0.040 & 0.638 \\
\hline E8: Interact with like-minded people & -0.086 & 0.149 & 0.761 & -0.123 & 0.565 \\
\hline $\begin{array}{l}\text { E9: Recommendation from like-minded } \\
\text { people }\end{array}$ & 0.000 & 0.094 & 0.747 & -0.013 & 0.594 \\
\hline $\begin{array}{l}\text { E10: Exchange idea and compare experi- } \\
\text { ence }\end{array}$ & 0.132 & -0.186 & 0.710 & 0.094 & 0.598 \\
\hline $\begin{array}{l}\text { E11: To be recognized when purchasing } \\
\text { again }\end{array}$ & 0.201 & -0.178 & 0.385 & 0.365 & 0.440 \\
\hline I1: Enjoy using Internet shopping & 0.596 & 0.342 & -0.003 & -0.047 & 0.548 \\
\hline I2: Be happy when using Internet shopping & 0.581 & -0.016 & -0.086 & 0.495 & 0.666 \\
\hline $\begin{array}{l}\text { I3: Be delighted with experience of Internet } \\
\text { shopping }\end{array}$ & 0.551 & 0.010 & -0.048 & 0.478 & 0.641 \\
\hline I4: Stimulate curiosity & 0.690 & 0.145 & 0.102 & -0.061 & 0.596 \\
\hline $\begin{array}{l}\text { I5: Provide customers with the product } \\
\text { /supplemental information that they are } \\
\text { interested in }\end{array}$ & 0.534 & 0.061 & 0.134 & 0.169 & 0.477 \\
\hline $\begin{array}{l}\text { I6: Offers options to perform task in differ- } \\
\text { ent ways }\end{array}$ & 0.464 & 0.061 & 0.196 & 0.137 & 0.421 \\
\hline $\begin{array}{l}\text { I7: Opportunity to make oneself appear } \\
\text { fashionable }\end{array}$ & 0.390 & -0.072 & 0.376 & 0.092 & 0.435 \\
\hline \multirow[t]{2}{*}{$\begin{array}{l}\text { I8: Boast of being the first one who possess } \\
\text { a product }\end{array}$} & 0.683 & 0.017 & 0.027 & -0.276 & 0.462 \\
\hline & & & & & Total \\
\hline Sum of squares (eigenvalues) & 6.238 & 1.779 & 1.288 & 1.027 & 10.332 \\
\hline Percentage of trace & 32.83 & 9.36 & 6.78 & 5.41 & 54.38 \\
\hline Cronbach's alpha (Overall $=0.880)$ & 0.820 & 0.739 & 0.774 & 0.584 & \\
\hline
\end{tabular}


What are the Benefits of Continued Purchasing through the Internet?

A Study of South Korean Consumers

Table 4. Correlation matrix of the factors

\begin{tabular}{|l|l|l|l|l|}
\hline Factors & $\begin{array}{l}\text { Intrinsic } \\
\text { factor }\end{array}$ & Time Saving & $\begin{array}{l}\text { Social adjustment \& } \\
\text { self-enhancement }\end{array}$ & $\begin{array}{l}\text { Money } \\
\text { Saving }\end{array}$ \\
\hline Intrinsic factor & 0.680 & & & \\
\hline Time Saving & 0.251 & 0.692 & & \\
\hline Social adjustment \& self-enhancement & 0.419 & 0.254 & 0.689 & 0.648 \\
\hline Money Saving & 0.257 & 0.267 & 0.261 & \\
\hline
\end{tabular}

Table 5. Results of Multiple Regression Analysis

\begin{tabular}{|c|c|c|c|c|}
\hline & Unstandardized Coefficients & Standardized Coefficients & \multirow{2}{*}{ t } & Sig. \\
\cline { 1 - 3 } & $\mathrm{B}$ & Beta & & \\
\hline Intrinsic factor & 0.351 & 0.353 & 13.416 & 0.000 \\
\hline Time Saving & 0.259 & 0.258 & 10.330 & 0.000 \\
\hline $\begin{array}{c}\text { Social adjustment \& } \\
\text { self-enhancement }\end{array}$ & 0.050 & 0.050 & 1.906 & 0.057 \\
\hline Money Saving & 0.312 & 0.304 & 12.144 & 0.000 \\
\hline
\end{tabular}

\section{Results of Multiple Regression Analysis}

A multiple regression analysis was conducted to investigate the impact of perceived benefits on the intention to continue purchasing in Internet shopping. Table 5 shows the results of the multiple regression analysis for continuance of purchasing $(R 2=0.458)$. According to the beta coefficients, the factor that has the highest impact on the continuance of purchasing behavior is intrinsic factor $(\beta=0.35 ; p<0.01)$, followed by money saving $(\beta=0.30$; $p<0.01)$, and time saving $(\beta=0.26 ; p<0.01)$. Social adjustment and self-enhancement $(\beta=0.05 ; p>0.05)$ is statistically insignificant to the continuance of purchasing behavior in Internet shopping. As a result, the hypotheses $\mathrm{H} 1, \mathrm{H} 2, \mathrm{H} 5, \mathrm{H} 6$, and $\mathrm{H} 7$ were supported, and $\mathrm{H} 3$ and $\mathrm{H} 4$ were rejected.

The results showed that not only extrinsic benefits but also intrinsic benefits influenced the online customers' intention to continue shopping online. Surprisingly, intrinsic benefits have the most significant effect on intention to continue shopping online. Internet shopping impressed online customers by arousing their curiosity and offering enhanced shopping experiences. The Internet shopping website gives consumers a different shopping experience because the interaction between the merchant and the consumer is more engaging and enjoyable [5]. Although Koufaris et al. [18] argued that enjoyment in internet shopping seemingly does not influence repeat customers to return, our positive significance of the intrinsic factor confirmed that online customers have an intrinsically enjoyable experience on-line that makes them continue purchasing through the Internet. The seond most significant factor is extrinsic benefits in terms of saving money. Saving time is the least significant factor. Purchasing items through Internet shopping saved customers' time in shopping and finding information and saved them money, because online prices are lower than offline prices of the same products. This indicated that online customers intend to continue purchasing in Internet shopping because it can solve their problems i.e., lack of time and lack of finances. The results also suggest that offline customers may turn to purchasing through the Internet to solve these problems.

Extrinsic benefits in terms of social adjustment and self-enhancement are insignificantly related with the intention to continue purchasing through the Internet. This result suggested that it is unnecessary for online customers to interact and exchange ideas with other customers who have similar interests or attitudes when they purchased through the Internet. It seemed that support in purchasing the items recommended by like-minded customers did not make them purchase again through the Internet. In addition, giving an acknowledgement to online customers who come back to purchase again is unlikely to be a reason for them to do so. This may be because Internet shopping websites do not provide enough services promoting social adjustment and self-enhancement benefits to online customers. For example, although they want a recommendation from like-minded customers before making a purchase, this option is not always provided by Internet shopping websites. 
It is interesting that online customers continued purchasing through the Internet because they were given opportunities to boast of being the first one who possessed the product. These perceptions were regarded as intrinsic benefits that are abstract and difficult to evaluate in terms of fashion involvement.

Figure 1 presents the research model and the results of multiple regression analysis.

\section{Conclusion and Implications}

This paper is one of the first studies to try to determine whether perceived benefits affect customers' intention to continue purchasing through the Internet. 998 samples collected from online customers in the EC market of South Korea were analyzed by using multiple regression analysis. The results confirm that not only extrinsic benefits (savings time and money) but also intrinsic benefits (pleasure, novelty, and fashion involvement) have significant positive effects on customers' intention to continue purchasing through the Internet. The findings show that people who consider both extrinsic and intrinsic benefits of online purchasing were more likely to purchase again in Internet shopping. Therefore, we call for technological development to provide techniques and services for ensuring online customer's benefits that minimize time and cost of purchasing, improve enjoyment and pleasantness of online purchasing, and provide means to help customers arouse their curiosity when coming back to purchase again through Internet shopping.

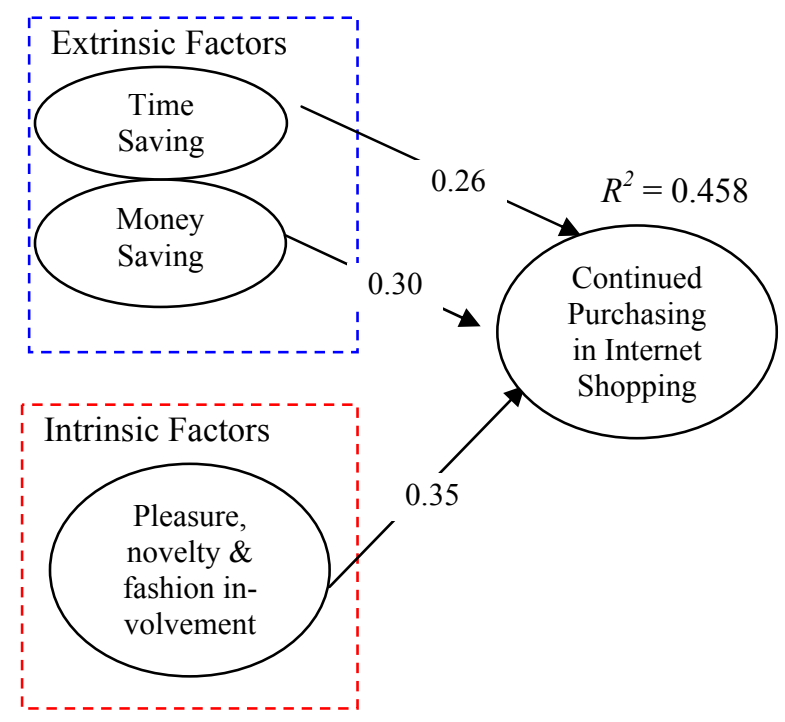

Figure 1. Research results

Our findings imply that the perceived intrinsic benefits in terms of pleasure and novelty are important for encouraging online customers to continue purchasing in Internet shopping. Thus, it seems that these benefits should be offered to online customers.

Customers found that they were delighted with their experience of Internet shopping and their interacting with Internet shopping stimulated their curiosity. Internet shopping websites need to satisfy customers' curiosity by, for example, offering several options of payment, enhancing interactive and attractive interface, offering promotions to customers, and displaying specific products or content to a certain type of customer.

Online customers would come back to purchase again if they got product or supplemental information. For online customers who want to get product instructions, the Internet shopping website should provide another webpage. For example, a cosmetics online shopping website could provide another webpage to instruct their customers on how to use and apply make-up.

\section{Limitations and Directions for Future Re- search}

Despite several significant findings, we acknowledge three limitations in our study. First, our study did not focus on any products, services, or Internet shopping websites. The empirical results for continuance intention may be biased or awry. For example, the respondents may have focused only on particular products/services or products that are not sold on the Internet. The perceived benefits factor influencing continuance intention in purchasing through Internet shopping for a particular product, service or Internet shopping website may be different from those we asserted in this study. We should be cautious in applying these results to an Internet shopping website selling a particular product and service. Second, the scope of this study is to focus on benefits in terms of extrinsic and intrinsic benefits. There may be other factors that affect the continuance intention such as payment modes and delivering time. Finally, the measures of perceived benefits developed in this study are the first step in exploring how customers' intention to continue purchasing in Internet shopping are influenced by their perceptions of benefits gained from purchasing through Internet shopping. The measurement of social adjustment, self-enhancement, and fashion involvement should be further refined.

Future researchers may pursue a number of different options. First, a longitudinal study may apply to study developmental trends across the life span of consumer perceptions and to observe the differences in their perceptions. The longitudinal study involves repeated studies and observations of the same items over long periods of time. Unlike cross-sectional data used in this study, longitudinal study can track the same people, and therefore the differences observed in those people are less likely to be the result of cultural differences across generations. Second, data mining technique may apply to both cross-sectional and longitudinal data in order to do customer profiling, to predict customer preferences, and to do trends analysis. Third, our model has been validated 
by and well explains South Korean online customers' intention to continue purchasing through the Internet. To generalize this model, it should be validated with respondents from the bigger EC markets such as the USA and China. Moreover, a comparative study of the repurchasing intentions of online customers from different nationalities should be done on the basis of the same model. The differences regarding the customers' intention to continue purchasing in Internet shopping will yield insights that can help Internet shopping websites better retain customers in different world market segments.

\section{REFERENCES}

[1] A. Bhattacherjee, "An Empirical Analysis of the Antecedents of Electronic Commerce Service Continuance", Decision Support Systems, Vol. 32, 2001, pp. 201-214.

[2] B. Vatanasombut, A.C. Stylianou, and M. Igbaria, "How to Retain Online Customers", Communication of the ACM, Vol. 47, No. 6, June 2004, pp. 65-69.

[3] Cochran, W. G.: Sampling Techniques, John Wiley \& Sons 1977.

[4] D.J Kim, D.L Ferrin, H.R. Rao, "A Study of the Effect of Consumer Trust on Consumer Expectations and Satisfaction: the Korean Experience", Proc. International Conference on E-Commerce, Pittsburgh, USA, 2003, pp. 310-315.

[5] D.L. Hoffman, and T.P. Novak, "Marketing in Hypermedia Computer-Mediated Environments: Conceptual foundations", Journal of Marketing, Vol. 60, No. 3, 1996, pp. 50-68.

[6] D.R. Campbell, and D.W. Fiske, "Convergent and Discriminant Validation by Multitrait-Multimethod Matrix", Psychological Bulletin, Vol. 56, No. 2, 1959, pp. 81-105.

[7] F.D. Davis, R.P. Bagozzi, and P.R. Warshaw, "Extrinsic and Intrinsic Motivation to Use Computers in the Workplace", Journal of Applied Social Psychology, Vol. 22, No. 14, 1992, pp. 1111-1132.

[8] G.A. Churchill, "A Paradigm for Developing Better Measures of Marketing Constructs", Journal of Marketing Research, Vol. 16, No. 1, 1979, pp. 64-73.

[9] Hair et al., Multivariate Data Analysis, 6th Ed., Prentice-Hall, 2006.

[10] I.K. Chung, and M.M. Lee, “A Study of Influencing Factors for Repurchase Intention in Internet Shopping Malls", Proc. International Parallel and Distributed Processing Symposium, Nice, France, 2003, pp. 243a.

[11] J. Aberg, and N. Shahmehri, "An Empirical Study of Human Web Assistants: Implications for User Support in Web Information Systems", CHI, Vol. 3, No. 1, 2001, pp.404-411.
[12] J. Lee, J. Kim, and J.Y. Moon, "What Makes Internet Users Visit Cyber Stores Again? Key Design Factors for Customer Loyalty", CHI Letters, Vol. 2, No. 1, 2000, pp. 305-312.

[13] J.Y. Bakos, "Reducing Buyer Search Costs: Implications for Electronic Marketplaces", Management Science, Vol. 43, No. 12, 1997, pp. 1676-1692.

[14] K. Atchariyachanvanich, H. Okada, and N. Sonehara, "What Keeps Online Customers Repurchasing through the Internet?" ACM SIGecom Exchanges, Vol. 6, No. 2, 2006, pp. 47-57.

[15] K.L. Hui, B.C.Y. Tan, and C.Y. Goh, "Online Information Disclosure: Motivators and Measurements", ACM Transactions on Internet Technology, Vol. 6, No. 4, 2006, pp. 415-441.

[16] M.J. Sirgy, "Self-Concept in Consumer Behavior: A Critical Review", Journal of Consumer Research, Vol. 9, No. 3, Dec. 1982, pp. 287-300.

[17] M. Koufaris, "Applying the Technology Acceptance Model and Flow Theory to Online Consumer Behavior", Information System Research, Vol. 13, No. 2, 2002, pp. 205-223.

[18] M. Koufaris, A. Kambil, and P.A. LaBarbera, "Consumer Behavior in Web-Based Commerce: An Empirical Study", International Journal of Electronic Commerce, Vol. 6, No. 2, Winter 2001-2002, pp. 115-138.

[19] National Internet Development Agency of Korea, Survey on the Computer and Internet Usage, Ministry of Information and Communication, South Korea, August 2006.

[20] National Internet Development Agency of Korea, Survey on the Computer and Internet Usage, Ministry of Information and Communication, South Korea, February 2008.

[21] Republic of KOREA e-Commerce, Overall Market Trends. Available at http://www.ecommerce.or.kr/

[22] R.-A. Shang, Y.-C. Chen, and L. Shen, "Extrinsic versus Intrinsic Motivations for Consumers to Shop On-line", Information \& Management, Vol. 42, 2005, pp. 401-413.

[23] R. Goodwin, R.B. Ball, "What Marketing Wants the CEO to Know", Marketing Management, Vol. 12, No. 5, 2003, pp. 18-23.

[24] R.I. Haley, "Benefit Segmentation: A Decision-Oriented Research Tool”, Marketing Management, Vol. 4, No. 1, 1995, pp. 59-62.

[25] S.L. Jarvenpaa, and P.A. Todd, "Consumer Reactions to Electronic Shopping on the World Wide Web", International Journal of Electronic Commerce, Vol. 1, No. 2, 1997, pp. 59-88.

[26] Turban et al., Electronic Commerce 2002: A Managerial Perspective, Prentice-Hall, 2002.

[27] T.P. Liang and H.J. Lai, "Effect of Store Design in Consumer Purchases: An Empirical Study of On-line Bookstores", Information \& Management, 
Vol. 39, No. 6, 2002, pp. 431-444.

\section{Appendix A}

Extrinsic benefits:

E1* Using Internet shopping is convenient.

E2* Using Internet shopping saves me time.

E3 Using Internet shopping would make it easier for me to shop or find information.

E4* Using Internet shopping would enable me to shop or find information more quickly than using traditional stores.

E5* Using Internet shopping saves me money.

E6* Internet shopping offers lower prices than traditional stores for the same products.

E7* Internet shopping allows me to interact with other customers in EC communities.

E8* I should be given chances to interact with other like-minded people when I purchase through the Internet.

E9* Internet shopping recommends other things to purchase that other like-minded people appreciate.

E10* Internet shopping allows me to exchange ideas as well as compare experiences.

E11 Internet shopping recognizes me when I purchase through the Internet again.

Intrinsic benefits:

I1* I enjoy using Internet shopping.

I2* I am very happy to purchase products through Internet shopping.

I3* I am delighted with my experience of Internet shopping.

I4* Interacting with Internet shopping stimulates my curiosity.

I5* Internet shopping provides me with the products and supplemental information that I am interested in.

I6 When I purchase through the Internet, Internet shopping websites offer me options to perform tasks in different ways.

I7 When I purchase through the Internet, it gives me opportunities to make myself appear fashionable.

I8* I like to boast of being the first one who possesses a product.

* Scales remained in exploratory factor analysis.

\section{AUTHORS’ BIOGRAPHIES}

Kanokwan Atchariyachanvanich is a postdoctoral researcher at National Institute of Informatics, Japan. She received a BS in Information Technology from Assumption University, Thailand in 1999, an MS in Information Management from the Asian Institute of Technology in 2001, and a PhD from the Graduate University for Advanced Studies, Japan in 2007. Her research interests include critical factors in the success of electronic commerce and behavioral issues in electronic commerce.

Hitoshi Okada is an Associate Professor at the National Institute of Informatics, Japan. He got his Bachelor of Public Law (LLB) and Bachelor of Private Law (LLB) from the University of Tokyo, Japan. He completed his MA at the Osaka School of International Public Policy at Osaka niversity and got his PhD in International Public Policy from Osaka University, Japan. His current research topic is the law and economics of e-money and e-commerce.

Noboru Sonehara is a Professor of the Information and Society Research Division, at National Institute of Informatics since 2004. Previously, he was Project Manager, Content Commerce Project, at NTT Cyber Solutions Laboratories from 2001 to 2004. He received a BE and ME from Shinshu University, Japan in 1976 and 1978, respectively. He received a PhD in 1994.He received the IFS image coding excellent paper award from the Institute of Image Electronics Engineers (IIEE) of Japan in 1993. He has been a Director of the Information and Society Research Division since 2006. 